\title{
La memoria en tiempos globalizados: la Guerra Civil española en dos novelas alemanas contemporáneas
}

\author{
JENNY Augustin \\ Heinrich-Heine-Universität Düsseldorf (Alemania) \\ orcid.org/0000-0002-6931-1267 \\ Presentación: 29 dic. 2019 | Aceptación: 5 jun. 2020 | Publicación: 31 oct. 2020
}

Cita recomendada: Augustin, Jenny. 2020. «La memoria en tiempos globalizados: la Guerra Civil española en dos novelas alemanas contemporáneas». Dictatorships \& Democracies. Journal of History and Culture 8: 127-158. doi: https://dx.doi.org/10.7238/dd.voi8.3180

Resumen: En este trabajo se analizan dos novelas alemanas contemporáneas que aportan una perspectiva transnacional a los debates de la conmemoración de la Guerra Civil y del nacionalsocialismo alemán: Blutorangen (Boos 2015) y Archipel (Mahlke 2018). Tras presentar los conceptos de «memoria cosmopolita» (Levy \& Sznaider 2002), «memoria multidireccional» (Rothman 2009) y «memoria transareal» (Ette 2010), se analizará si se pueden aplicar a ambas novelas. Además, se estudiará qué imagen transmiten sobre la Guerra Civil, el franquismo y la sociedad española.

Palabras clave: Guerra Civil, nacionalsocialismo, Holocausto, novela alemana, memoria multidireccional, Verena Boos, Inger-Maria Mahlke

\section{Memory in Global Times: The Spanish Civil War in Two Contemporary \\ German Novels}

Abstract: This article analyzes how two recently published German novels contribute a transnational perspective to the debates on remembrance of the Spanish Civil War and German National Socialism: Blutorangen (Boos 2015) and Archipel (Mahlke 2018). After introducing the concepts of «cosmopolitan memory» (Levy \& Sznaider 2002), «multidirectional memory» (Rothman 2009) and «transareal memory» (Ette 2010), it will be considered whether these concepts can be applied to both novels. Furthermore, the article will examine how the two German novels portrait the Spanish Civil War, Francoism and Spanish society.

Keywords: Spanish Civil War, National Socialism, Holocaust, German novel, multidirectional memory, Verena Boos, Inger-Maria Mahlke

Desde hace algunos años se están conmemorando los grandes aniversarios de sucesos históricos que han cambiado nuestra convivencia a nivel global, como el septuagésimo aniversario del fin de la Segunda Guerra 
Mundial en 2015 o el octogésimo aniversario del final oficial de la Guerra Civil española y del inicio de la Segunda Guerra Mundial en 2019. Otro hito importante es el trigésimo aniversario de la caída del muro de Berlín con la posterior disolución de la Unión Soviética, la reunificación de las dos Alemanias y la fundación de la Unión Europea. Los debates que dominan el discurso europeo hoy día son: ¿cómo hemos convivido en el pasado, cómo queremos convivir en el futuro y qué Europa queremos tener? ${ }^{1}$

Tanto en Alemania como en España, el tema de la memoria histórica tiene una presencia irrefutable en los debates colectivos (Olmos 2009, 7). El cine y la literatura ficcional contribuyen a estos discursos y son de suma importancia, ya que contribuyen a nuestra noción sobre el pasado (Gómez López-Quiñones 2006, 283). En el campo literario alemán de las primeras décadas del siglo xxi se puede observar un claro interés por temas vinculados a la memoria histórica, como, por ejemplo, los retos de la reunificación (Unterleuten, Zeh 2016), la migración desde el este europeo hacia Alemania (Herkunft, Stanišić 2019) y el nacionalsocialismo, tema constantemente presente desde hace unos cuarenta años. ${ }^{2}$ En la actualidad, el debate se centra especialmente en cómo las jóvenes generaciones valoran la vida de sus abuelos durante el nacionalsocialismo, ya sea como víctimas (Die Fische von Berlin, Hummel 2005) o como verdugos (Himmelskörper, Dückers 2003). ${ }^{3}$ En este campo literario brevemente esbozado, están surgiendo novelas que resultan especialmente interesantes para revaluar el pasado, pues abordan la temática desde una perspectiva que

1 Algunos ejemplos de estos debates actuales son el incremento de la inmigración a partir de 2015, la creciente influencia de partidos euroescépticos de derechas, como la AfD en Alemania o Vox en España, y el brexit de 2020. Véase la reciente publicación de Ramiro Troitiño et al. (2020) sobre los retos a los que se enfrenta la Unión Europea actualmente.

2 Asimismo, en el cine alemán surgen regularmente películas nuevas que tematizan el nacionalsocialismo, la Segunda Guerra Mundial y el Holocausto. En cuanto al género, en los últimos años han predominado los dramas judiciales (Im Labyrinth des Schweigens, Ricciarelli 2014; Der Staat gegen Fritz Bauer, Kraume 2015) y las adaptaciones de la literatura testimonial (Als Hitler das rosa Kaninchen stahl, Link 2019, que está por estrenarse en los cines de España). Para un análisis sobre la representación del pasado en el cine alemán reciente, véase Fiedler (2006).

3 Forkel (2019) ofrece una panorámica de las novelas contemporáneas alemanas sobre el nacionalsocialismo. 
no se limita únicamente a un entorno nacional. ${ }^{4}$ Las novelas Blutorangen (Naranjas de sangre), de Verena Boos (2015), y Archipel (Archipiélago), de Inger-Maria Mahlke (2018), ocupan una posición peculiar, pues también tienen en consideración la historia española, creando así vínculos entre Alemania y España. ${ }^{5}$

El objetivo de este artículo es examinar si los conceptos de «memoria cosmopolita» (Levy \& Sznaider 2002), «memoria multidireccional» (Rothman 2009) 0 «memoria transareal» (Ette 2010) se pueden aplicar a las novelas Blutorangen (Boos 2015) y Archipel (Mahlke 2018) y, además, analizar la imagen que estas transmiten de la Guerra Civil, del franquismo y de la sociedad española. Por último, esto nos llevará a reflexionar sobre la función del texto literario en los debates colectivos: ¿puede la literatura ayudarnos a ampliar nuestros conocimientos sobre el pasado histórico? ¿Qué límites tiene el texto ficcional con tema histórico?

Mahlke y Boos son dos escritoras que representan la generación de los alemanes nacidos a finales de los años setenta que de pequeños presenciaron la caída del muro de Berlín y que, más tarde, probablemente aprovecharon el programa de intercambio europeo Erasmus. Las dos tienen vínculos biográficos con España. ${ }^{6}$ Elegí estas dos novelas hasta ahora poco estudiadas ${ }^{7}$ para contribuir, con su análisis, a las investigaciones sobre la percepción que tiene la novelística alemana contemporánea sobre el pasado de los países europeos vecinos y las consecuencias que ello tiene para la propia identidad histórica y para la creación de una memoria compartida y de un futuro común. ${ }^{8}$

4 Para más información sobre la influencia transnacional en la narrativa española sobre la Guerra Civil, véanse Hansen (2015) y Jünke (2015).

5 Desde el inicio de la Guerra Civil, han surgido textos narrativos y testimoniales tanto en Alemania como en otros países europeos que han abordado esta temática desde distintas perspectivas (véase Bannasch \& Holm 2005; Asholt et al. 2009). En cambio, la narrativa actual no está escrita por testigos o combatientes que participaron en la Guerra Civil, sino que son las jóvenes generaciones las que toman la palabra.

6 Boos vivió en Valencia y Barcelona (Verena Boos, s. f.). Inger-Maria Mahlke, hija de una tinerfeña y un alemán, creció entre Lübeck y Tenerife (Rohwohlt, s. f.-a).

7 Véanse Auweiler (2019) y Domínguez (2019).

8 Marco Thomas Bosshard (2016) analiza la perspectiva contraria, es decir, la representación del nacionalsocialismo en la literatura española. Esta manera de estudiar las perspectivas transnacionales también tiene un considerable interés a nivel europeo: un buen ejemplo de ello sería la novela 
Además de por sus temas paralelos, el corpus elegido se adecua a este análisis porque ambas novelas fueron publicadas recientemente y contaron con una recepción favorable en Alemania, ${ }^{9}$ lo que aparentemente se debe, entre otras cosas, a su carácter europeo: en 2018, el jurado del prestigioso Premio Alemán del Libro alabó el modo en el que Mahlke tematiza la «historia de las dictaduras europeas del siglo xx» (Deutscher Buchpreis, s. f.). Se trata, pues, de mostrar los vínculos que existen entre los fascismos en Alemania y España. Por un lado, tal afirmación es problemática por provenir de una organización alemana, ya que desvía la atención de la propia culpa de Alemania. Pero, por otro lado, subraya un hecho sumamente importante: la imposibilidad de entender las historias nacionales sin considerar el contexto europeo.

En cuanto a la recepción de las novelas en España, la novela de Boos ha sido traducida al español como Naranjas de Sangre (Plataforma, 2017) y al catalán como Taronges de sang (Bromera, 2017). La autora participó en varias presentaciones en España ${ }^{10}$ y se publicaron unas cuantas reseñas del libro (Nopca 2017, Llopart 2017). ${ }^{11}$ En cambio, la novela de Mahlke, que es más reciente, aún no ha sido traducida al español. ${ }^{12}$ De todos modos, hubo reacciones favorables en los medios de comunicación catalanes y canarios ante la premiación de esta obra (Suomi 2018, La Vanguardia 2018).

A continuación, en el primer apartado, se ofrecen algunas observaciones sobre las distintas teorías para precisar las particularidades y retos de la memoria en tiempos globalizados. Después, en el segundo y en el

francesa Pas pleurer, de Lydie Salvayre, galardonada con el Premio Goncourt en 2014, que trata sobre la Guerra Civil española y que mezcla el francés con el castellano. Véase Arraéz (2017).

9 Verena Boos ganó el Mara-Cassens-Preis, el Debütpreis des Buddenbrookhauses, el GerhardBeier-Preis y el Grimmelshausen-Förderpreis con su novela Blutorangen (Boos 2018). Mahlke ganó el Premio Alemán del Libro en 2018.

10 Se pueden ver los vídeos de sus presentaciones en el Librerío de la Plata y en el Goethe-Institut de Barcelona en los siguientes enlaces: https://www.youtube.com/watch?v=abrA2lLHGT4; https:// www.youtube.com/watch?v=cs2HfkvrooE.

11 Resulta interesante que las reseñas mencionen los vínculos históricos de ambos países, tal y como se puede advertir en Nopca (2017), que toma una cita de la autora como título para su artículo: «Verena Boos: "Espanya i Alemanya tenen una història de violència compartida." L'escriptora connecta Hitler i Franco a la seva primera novella, Taronges de sang».

12 No obstante, la página web de la editorial alemana anuncia que la editorial Vegueta adquirió los derechos para la traducción al español y al catalán (Rowohlt, s. f.-b). Resultaría fructífero analizar la recepción de la novela en España una vez haya sido traducida. 
tercero, se analizará cómo las novelas Blutorangen, de Boos, y Archipel, de Mahlke, experimentan con el concepto de la memoria y lo sitúan en un contexto europeo.

\section{La memoria en tiempos globalizados}

Según el sociólogo francés Maurice Halbwachs, cada individuo pertenece a varios marcos sociales que forman su identidad, y las memorias individuales crean una memoria colectiva que no es homogénea (Halbwachs 1976, 146 y 296). ${ }^{13}$ Las observaciones de Halbwachs se pueden transferir a la actualidad del siglo xxi, en la que la acelerada globalización influye en los procesos de memoria, creando nuevos marcos sociales: «[I]t has become impossible to understand the trajectories of memory outside a global frame of reference» (Assmann \& Conrad 2010, 2). En los estudios sobre este tema, han surgido varios intentos de definir la influencia de lo global en los procesos de memoria. ${ }^{14}$ Los sociólogos Daniel Levy y Natan Sznaider (2002) proponen salir del marco nacional para analizar la llamada «memoria cosmopolita» (cosmopolitan memory). No se trata de borrar la perspectiva nacional, sino de reparar en las fuertes interacciones existentes entre el nivel global y el nivel local (Levy \& Sznaider 2002, 92). La cosmopolitización de la memoria permite la identificación con representaciones culturales que han surgido en otros países, para así asumir otro punto de vista que tenga en cuenta la historia y la memoria ajenas (Levy \& Sznaider 2002, 103). Para ejemplificar el concepto de «memoria cosmopolita», los autores emplean la conmemoración del Holocausto en

13 Conforme a Jan Assmann (1988), existen dos niveles de memoria: la memoria comunicativa y la memoria cultural. La memoria comunicativa se basa en los recuerdos transmitidos a través de las generaciones y tiene un alcance de aproximadamente 80-100 años (Assmann 1988, 11). El concepto de «memoria cultural», en cambio, se refiere al nivel institucional de la memoria y abarca elementos como los rituales, monumentos o textos. La memoria cultural se define por las siguientes características: siempre está vinculada a un grupo determinado; representa una reconstrucción del pasado; se manifiesta en el lenguaje, las imágenes y los rituales; se define por un alto grado de organización; es normativa, y es reflexiva (Assmann 1988, 13-15).

14 Para una panorámica de las políticas actuales de la memoria entre lo global y lo local, véase Guixé i Coromines (2016). 
Alemania, Estados Unidos e Israel: ${ }^{15}$ a principios de este siglo, los gobiernos de distintos países firmaron la Declaración de Estocolmo, en la que reconocieron su responsabilidad compartida a la hora de conmemorar el Holocausto y se comprometieron a velar por los derechos humanos en el futuro. ${ }^{16}$ Se puede constatar, entonces, que los procesos de memoria no solamente tienen que ver con el pasado, sino que son fundamentales para la construcción de un futuro en común (Levy \& Sznaider 2002, 100 y s.). Michael Rothberg, por su parte, propone aplicar el concepto de «memoria multidireccional»(multidirectional memory) para caracterizar las interacciones interculturales de los distintos procesos de memoria: «[I]t has the potential to create new forms of solidarity and new visions of justice» (Rothberg 2009, 5). Así pues, la literatura podría desempeñar un papel decisivo, ya que ofrece un espacio para reflexionar, criticar y experimentar con las posibilidades y consecuencias de la memoria en tiempos globalizados. El filólogo alemán Ottmar Ette analiza cómo las llamadas novelas «transareales» $(2010,167$ y 196) ponen a prueba las distintas formas de convivencia, no solo a nivel nacional, sino también a nivel europeo e incluso a nivel global. ${ }^{17}$ Para concebir el mundo en continuo movimiento, Ette emplea la metáfora de la isla. Al ampliar el sentido de «isla» se crea

15 No obstante, Aleida Assmann y Sebastian Conrad aciertan en advertir que la memoria del Holocausto no es compartida universalmente, sino que es importante entender el marco cultural específico en el que tiene relevancia. En cambio, muchos países del llamado «sur global» desarrollan una memoria compartida ante el telón de fondo de una violenta experiencia colonial (Assmann \& Conrad 2010, 8 y s.).

16 Se puede leer el texto de la declaración en la página oficial de la Alianza Internacional para la Memoria del Holocausto (2000). En lo que concierne al Estado español, Alfons Aragoneses (2017, 192) muestra cómo, a partir de 2005, las instituciones españolas han colaborado en la construcción de una conmemoración transnacional del Holocausto. No obstante, señala que la integración del estudio del Holocausto en el currículo escolar a partir de 2014 se limita a concebirlo como un fenómeno ocurrido fuera de España. No está previsto, por ejemplo, estudiar la historia de los republicanos españoles deportados a los campos de concentración nazis, aspecto que sería esencial para llegar a una verdadera conmemoración transnacional del Holocausto.

17 En ZusammenLebensWissen, Ette (2010, 165-198) ofrece un análisis de la literatura sobre el Holocausto (Semprún, Wajsbrot) para mostrar cómo construye la visión de una Europa multilingual y multicultural que podrá surgir a condición de que se establezca una nueva política memorial. Según Ette, es imposible escribir sobre la literatura europea sin tener en cuenta los distintos movimientos transareales. Analiza, por ejemplo, la obra de José F. A. Oliver, un español que creció en la Selva Negra alemana y cuya literatura no se reduce a una etiqueta nacional (Ette 2010, 186 y s.). 
[...] a world consisting of islands of all types of locations and sizes, shapes and figures. The dominating worldview is not a continental one, unified and continuous [...], but a highly discontinuous and fragmented worldview [...]. It is [...] a highly complex, fragmented world of islands that evades the command of a single power and escapes the continuities of human history and religious salvation. Despite the fact that every island is an element of an interconnected world, they nevertheless maintain their specific perspective within the unquestionable spherical unity of the planet. (Ette 2012, 23)

En vez de concebir el mundo como una entidad homogénea, Ette propone entenderlo en su complejidad, tomando en consideración su fragmentariedad («discontinuous and fragmented worldview»). Con ello, se despide de las grandes narrativas y de su linealidad, dando paso a una perspectiva insular. Al percibir el mundo como un conjunto de muchas islas, es posible combinar dos perspectivas: por un lado, cada isla tiene su singularidad («specific perspective»), mientras que, por otro, todas las islas del mundo están conectadas entre sí («every island is an element of an interconnected world»). De este modo, Ette concibe el mundo como una red que se encuentra en un estado de continuo movimiento.

¿Cómo se pueden canalizar estas teorías en una metodología para el análisis literario? Para analizar si los conceptos de «memoria cosmopolita», de «memoria multidireccional» o de «memoria transareal» se pueden aplicar a una novela específica, podemos explorar varios niveles del texto. A nivel extratextual, la traducción de una determinada novela y su presencia en los campos literarios de otros países son factores que influyen en la posible cosmopolitización de la obra. Esto nos lleva al segundo nivel, el paratexto (Genette 1987): se puede examinar si los escritores o las escritoras aluden a una memoria multidireccional en las entrevistas que ofrecen. Asimismo, también se puede estudiar si las peculiaridades del título, el diseño del epígrafe y las citas o fuentes mencionadas pueden sugerir el carácter transareal de la obra en cuestión. A nivel intertextual e interdiscursivo, una novela cosmopolita tiene vínculos intertextuales con obras de la literatura mundial, y es imprescindible preguntarse a qué sucesos históricos y discursos memorialísticos remite la novela. El idioma utilizado y el code-switching, por su parte, son criterios intratextuales, 
como también lo son el espacio y el tiempo en el que se sitúa la trama y la posible biografía transnacional de los personajes. Asimismo, los campos semánticos empleados pueden hacer referencia a los procesos de memoria. A nivel del discours, sería interesante analizar desde qué perspectiva se narra la historia; si hay, por ejemplo, un cambio de instancias narrativas o una estructura ácrona que rompe la secuencia cronológica mediante el empleo de analepsis o prolepsis. ${ }^{18}$

En este artículo se emplea el método del close reading para poder, de este modo, vincular los distintos niveles de la narración. A través del análisis de escenas particulares y detalles de la historia, se puede demostrar cómo el texto literario trabaja con el concepto de memoria y así deducir hasta qué grado la obra se puede considerar cosmopolita, multidireccional o transareal. En el siguiente apartado, empezaré con el análisis de la primera novela, Naranjas de sangre (Boos 2015).

\section{De las fronteras nacionales a las fronteras ideológicas: Blutorangen (Naranjas de sangre)}

El título de la novela, Naranjas de sangre, evoca una imagen con distintos matices. Visualmente, el rojo de la sangre hace alusión a la violencia. Es común asociar este color llamativo con el peligro. En cuanto al gusto, las naranjas de sangre difieren de las naranjas dulces porque tienen un sabor ácido y más amargo. Podemos entender esto de modo metafórico y considerar el sabor como «impresión que algo produce en el ánimo» (RAE 2014). Y de sabor amargo son los recuerdos de los sobrevivientes de la Guerra Civil y de la Segunda Guerra Mundial.

Al cuerpo de la obra lo precede un árbol genealógico de la familia española de Maite, la protagonista, y la familia medio alemana y medio española de Carlos. Las dos quedan entrelazadas con el matrimonio de estos personajes. El árbol genealógico abarca tres generaciones, el espacio temporal que alcanza, según Jan Assmann $(1988,11)$, la memoria comu-

18 La terminología empleada en el análisis de los textos literarios se basa en las definiciones elaboradas por Genette (1972). Véase también la lista elaborada por Astrid Erll (2017, 191-212) de los conceptos de «memoria cultural» $\mathrm{y}$ «memoria comunicativa» en el texto literario. 
nicativa. Con ello se tiene la impresión de que la novela se centra en los procesos de memoria individuales y familiares. No obstante, durante la lectura se hace patente que la memoria individual de Maite sirve de retrato de la sociedad española en un contexto europeo.

Otro aspecto paratextual que llama la atención es el apartado de «Fuentes y agradecimientos» que Boos $(2017 a, 377-379)$ ha añadido al final del libro, donde cita las obras historiográficas usadas. En cierto modo, esta parte del libro sirve como autolegitimación, ya que intenta subrayar que los hechos históricos mencionados se basan en investigaciones actuales y que su trama no es meramente ficticia. La escritora busca vincular su novela con el contexto sociopolítico. A partir de las fuentes elegidas por la autora podemos determinar si Naranjas de Sangre es un libro comprometido con la memoria cosmopolita: junto a las obras historiográficas alemanas sobre la Guerra Civil, también se mencionan fuentes anglófonas y españolas. ${ }^{19}$ Esto confirma que el modo de trabajo de Boos es multilingüe y multidimensional. Además, la escritora alaba el trabajo de organizaciones no gubernamentales como la Asociación para la Recuperación de la Memoria Histórica e incluso menciona haber participado en una exhumación en España (Boos 2017a, 378). Esto demuestra que la autora se familiarizó con las prácticas y los debates actuales en el país, adoptando, así, una posición clara a favor de la ARMH. Para los lectores alemanes con escasos conocimientos sobre la historia y las víctimas españolas del Holocausto, la mención de estas fuentes es de especial importancia, pues les posibilita llenar este vacío. Empleando los términos de Levy y Sznaider, se puede deducir que la lectura de esta novela logra que los lectores alemanes empaticen con las víctimas de España y sean conscientes de que la historia de su país está vinculada a la historia española. ${ }^{20}$

19 Las obras mencionadas son: Spaniards in the Holocaust, de Wingeate Pike; Gegenwart der Vergangenheit - Die Kontroverse um Bürgerkrieg und Diktatur in Spanien, de Pichler; Kampf der Erinnerungen: Der Spanische Bürgerkrieg in Politik und Gesellschaft, de Bernecker y Brinkmann, y Desenterrar las palabras: Transmisión generacional del trauma de la violencia política del siglo Xx en el Estado español, de Valverde (Boos 2017, 377 y s.).

20 En su reseña, el prestigioso periódico nacional Frankfurter Allgemeine Zeitung comenta que la novela recuerda los vínculos históricos entre Hitler y Franco, de los que hoy día muchos alemanes son poco conscientes (Teutsch 2015). Auweiler $(2019,255)$ incluso considera la novela como una contribución alemana a la literatura de la memoria española. 
La trama se centra en Maite, una joven valenciana que se va a estudiar a Múnich con una beca Erasmus en los años noventa (Boos 2017a, 297). En este viaje descubre el pasado siniestro de su padre, que luchó en la División Azul durante la Segunda Guerra Mundial y trabajó como guardia civil durante los años de posguerra (Boos 2017a, 156). ${ }^{21}$ Maite se enamora y se casa con Carlos, hijo de un español y de una alemana. En algún momento la protagonista conoce al abuelo de este, un español que, estando exiliado en Francia durante la Guerra Civil, fue detenido en un campo de internamiento en Angulema, desde el que fue deportado al campo de concentración de Mauthausen (Boos 2017a, 86 y s.). ${ }^{22}$ No obstante, tuvo suerte y pudo escapar del tren antes de llegar a este destino. Dialogando con Antonio, el abuelo, la protagonista descubre el pasado entrelazado entre España y Alemania y empieza a entender la historia violenta de su propio país.

La instancia narrativa hetero- y extradiegética asume la focalización interna de distintos personajes, cambiando frecuentemente la perspectiva. Así, a nivel narrativo, se crea la posibilidad de concebir una memoria multidireccional de acuerdo con Rothberg. La mayoría de las veces, la focalización interna se centra en Maite. Algunos de los personajes nunca se focalizan: el hijo de Antonio y la cocinera de la familia de Maite solo aparecen a través de los pensamientos de los demás personajes. De este modo, no forman parte de la memoria colectiva y asumen una posición marginal que no abandonan ni siquiera al final de la novela.

A veces se producen cambios narrativos en los que el narrador se dirige a Antonio en segunda persona. Esto ocurre por primera vez en un instante decisivo y traumático, en 1940, cuando Antonio se da cuenta de que ha perdido a su esposa e hijo (Boos $2017 a, 100$ y s.). Con la pérdida de su familia, se queda sin una red social. Además, el hijo ausente personifica el futuro imposible. Los cambios narrativos a la segunda persona se vuel-

21 Sobre la División Azul, unidad de soldados españoles que Franco envió a Alemania durante la Segunda Guerra Mundial, véase Moreno Juliá (2012).

22 La novela plasma un acontecimiento real: la deportación en tren de aproximadamente 900 hombres, mujeres y niños españoles de Angulema a Mauthausen, donde los hombres bajaban para permanecer en el campo de concentración mientras las mujeres y los niños seguían el camino hasta ser entregados al Gobierno franquista en la frontera entre Francia y España (Brenneis 2018, 10). 
ven a producir en 2004, cuando Antonio se enfrenta a su pasado traumático al viajar a su pueblo natal para la exhumación de su padre - quien representa el pasado perdido - de una fosa común:

Estás en tu antigua casa, muchos años después, y querrías tener tu bastón o una silla en la que poder reflexionar sobre este monstruoso lapso del tiempo, [...] volver a ser un niño, todos esos veranos, dos hermanos, padre y madre, la noche, la casa, la huida (y piensa, eso es lo que ocurre), la noche en la que arrastraron a su padre delante de dos faros (eso es lo que ocurre cuando se muere), el campo de refugiados y aquel tren, todo te pasa por delante, este brazo pesado y el vacío en los pulmones [...]. (Boos 2017a, 288)23

La sintaxis peculiar de esta frase larga en la que predomina el asíndeton muestra cómo el regreso a la casa natal desencadena una ola de recuerdos que inunda la mente de Antonio. Los recuerdos fragmentarios ( «la noche, la casa, la huida») se ven interrumpidos por sus pensamientos conscientes, marcados por los paréntesis, en los que reacciona ante el impacto de los recuerdos. El narrador alterna entre la tercera y la segunda persona («estás», «piensa», «te pasa»). Estos cambios marcan el reencuentro de Antonio con su propio pasado y con los momentos traumáticos que ha estado remprimiendo a causa de su gran carga violenta. Por un lado, muestran la disociación de la personalidad de Antonio; por otro, crean una cercanía con el personaje que posibilita empatizar con él. Esta escena refleja lo doloroso que puede ser el proceso de recuperación del pasado, que frecuentemente hace que vuelvan a surgir los recuerdos traumáticos. ${ }^{24}$ El arduo regreso del personaje a España se equipara con el regreso a la casa («estás en tu antigua casa»), que funciona como pars pro toto del país

23 «Du stehst in deinem alten Haus, so viele Jahre danach, und wünschst dir deinen Stock oder einen Stuhl, auf dem du deine Gedanken über diese monströse Zeitspanne denken könntest, [...] Kindsein, all diese Sommer, zwei Brüder, Vater und Mutter, die Nacht und das Haus und die Flucht (und er denkt, so ist das doch), die Nacht, da man den Vater an zwei Scheinwerfern hinauszog (so ist das doch, wenn man stirbt), das Lager und dieser Zug, alles zieht an dir vorbei, dieser schwere Arm und die Leere in den Lungen [...]» (Boos 2018, 312).

24 Véase, por ejemplo, el documental El silencio de otros (Carracedo \& Bahar 2018), que acompaña a varias familias durante las exhumaciones de sus seres queridos, enterrados en fosas comunes durante la Guerra Civil. 
natal que no fue nido de protección, sino el lugar del que Antonio tuvo que huir. El movimiento que implican las palabras «huida», «refugiados» $\mathrm{y}$ «tren» contrasta con la reclusión forzosa que se insinúa mencionando el «campo», sabiendo que se trata de un tren de deportación. El cuerpo de Antonio, impactado por los recuerdos, sufre y anhela tener un lugar de reposo («bastón», «silla»).

En vez de ser cronológica, la estructura temporal de la novela se caracteriza por entrelazar el presente con frecuentes analepsis hacia el pasado. El presente se sitúa entre los años 1990 - cuando Maite empieza a descubrir los vínculos entre su padre y la Wehrmacht- y 2004, momento en el que la familia viaja a España para la exhumación. Los capítulos intercalados que se sitúan en el pasado abarcan un periodo de tiempo de cuatro años, de 1939 y a 1942. Estos capítulos se centran en las experiencias de Antonio en España, Francia y Alemania (p. ej., Boos 2017a, 100-119) y de Francisco, el padre de Maite, en Rusia y España (p. ej., Boos 2017a, 167-178). ${ }^{25}$ Las secuencias situadas en el pasado nos acercan a la vida sentimental de estos personajes, ambos marcados por el sufrimiento y las experiencias de guerra que tuvieron lugar en un espacio transnacional. El lector concibe, así, las distintas perspectivas históricas de izquierdas y de derechas, perspectivas contrarias y encarnadas por Antonio y Francisco. Intercalando el pasado y el presente, la estructura temporal subraya los procesos de conmemoración y de recuperación del pasado desde el presente. También se muestra que las heridas del pasado siguen abiertas. El padre de Maite es de opiniones firmes e intenta justificar las acciones violentas cometidas por el bando de derechas durante la Segunda Guerra Mundial al ser confrontado por su hija:

25 Los nombres de ambos personajes aluden a figuras históricas de España que también se conocen en Alemania: Antonio comparte el nombre con Machado. Evoca la triste experiencia del escritor en su huida a Francia y la posterior muerte en Colliure, el pueblo donde yace su tumba, que, según $E l$ País, se puede considerar como «icono de la memoria republicana» (Rodríguez Marcos 2019). Francisco, el padre de Maite, lleva el mismo nombre que Franco, convirtiéndose así en la encarnación del discurso derechista. La elección de estos nombres en la novela facilita la adscripción de los personajes a distintos bandos políticos, pero a la vez puede ser criticada como una reafirmación de estereotipos. 
—En Rusia ahorcaron, fusilaron y deportaron a la gente. Además, también deportaron a españoles a Mauthausen y Buchenwald.

— ¡Estaba en su derecho! —Clavó el cuchillo y el tenedor en el pavo-. ¡Nuestro enemigo era el bolchevismo, que amenazaba con arrasar Europa! ¡Nuestra guerra fue una cruzada de las personas que creen en Dios! [...] ¡Eran gente sin fe y sin moral! Ya vimos aquí lo que eran capaces de hacer. [...] ¡Diez mil mártires en el Paracuellos!

— ¡Eso es mentira, son muchos menos! [...]

- Habían atacado a nuestra patria desde el interior y tuvieron que ser extraídos como un cáncer. - Su mano se dispara hacia arriba como una serpiente detrás del pavo. (Boos 2017a, 252 y s. $)^{26}$

En la discusión con Maite, el padre se comporta de manera violenta («clavó el cuchillo y el tenedor en el pavo») y los utensilios en sus manos parecen ser armas («cuchillo», «tenedor», «se dispara»). El pavo de Navidad alude, en este caso, a las víctimas anónimas mencionadas por Maite. La comparación del movimiento del padre con el de una serpiente, animal asociado a la traición y al mal, confiere una connotación negativa. Las numerosas interjecciones subrayan su estado de ira. Además, aparecen conceptos centrales de la jerga derechista («bolchevismo») y cristiana («cruzada», «mártires») creando así una visión binaria entre el nosotros («nuestro», «vimos») a un lado y el enemigo al lado opuesto. Llama la atención en esta cita que el padre hable de «nuestra guerra», sirviéndose de una imagen transnacional que equipara la Guerra Civil con la Segunda Guerra Mundial, así como la causa franquista con el nacionalsocialismo alemán. Las fronteras, en este caso, no se sitúan entre los españoles y los alemanes, sino entre la gente de derechas y la de izquierdas. Al repetir el padre de Maite la problemática metáfora del «cáncer», utilizada por los

26 «"Die haben in Russland die Leute erhängt, erschossen, deportiert. Die haben übrigens auch Spanier deportiert, nach Mauthausen und Buchenwald." "Das hatte seine Berechtigung!" Er rammt das Messer und die Fleischgabel in den Truthahn. "Unser Feind war der Bolschewismus, er drohte Europa zu überrollen! Unser Krieg war ein Kreuzzug der Menschen, die an Gott glauben! [...] Das waren Leute ohne Glauben und ohne Moral! Man hat hier ja gesehen, was die anrichten. [...] Zehntausend Märtyrer in Paracuellos!" "Das ist eine Lüge, es sind viel weniger!" [...]"Sie hatten unser Vaterland von innen befallen, und man musste sie wie einen Krebs herausschneiden.” Seine Hand schießt wie eine Schlange hinter dem Truthahn hervor» (Boos 2018, 272 y s.). 
nacionalsocialistas para justificar las matanzas del enemigo retratándolo como un ser degenerado y peligroso (Musolff 2010, 24), el texto crea un personaje anacrónico y estereotipado.

Tal y como se puede observar en el texto citado arriba, los lectores acompañan a Maite en el momento en el que se enfrenta al pasado de España y a los vínculos del país con Alemania. La mención explícita de los campos de concentración muestra a los lectores que los alemanes nazis también asesinaron a habitantes de otros países («españoles a Mauthausen»). Maite se ha informado y sabe descifrar la «mentira» pronunciada por su padre. Se niega a creer el mito de Paracuellos, representando así a las jóvenes generaciones que se liberan del poder de las antiguas élites y que cambian la percepción del pasado histórico. Los conflictos ideológicos se convierten en un conflicto de memoria.

Un aspecto problemático de la novela es que se centra con tanta vehemencia en los sucesos atroces ocurridos en España que parece implicar con ello que la labor de superación del problemático pasado alemán ya está prácticamente rematada. Esto se hace patente en la forma de caracterizar a los verdugos en la novela. La mayoría de ellos son anónimos, y casi todos son españoles. El único verdugo alemán que tiene nombre en la novela es el «tío Hans», miembro de la SS. Es un personaje unidimensional, retratado como hombre antipático y violento que muere poco después de la Segunda Guerra Mundial (Boos 2017a,132). La continuidad nacionalsocialista en la sociedad alemana tampoco se presenta con más detalle. Es más, se pone énfasis en la ayuda que diversos alemanes ofrecieron a Antonio al encontrarse perdido en Múnich en 1940 (Boos 2017a, 110-119). Parece ser un caso extremadamente hipotético: a la poca probabilidad de huir con éxito de un tren de deportación, ${ }^{27}$ se añade la poca

27 La historiadora Tanja von Fransecky (2014) analiza los intentos de fuga de los judíos de los trenes de deportación en Francia, Bélgica y los Países Bajos, mostrando que hubo más de 750 huidas documentadas. No obstante, explica que la mayoría de las personas que pudieron escapar tenía algún contacto con grupos o redes de resistencia, lo que les facilitó la decisión de escapar por tener una mayor capacidad de actuar y de informarse. Otro aspecto que menciona Von Fransecky es que la población alemana era considerada enemiga por los presos judíos, causa por la que no hubo tantos intentos de fuga en este territorio (Von Fransecky 2014, 335-340). Visto de este modo, la fuga de Antonio, motivada por asuntos personales, casi sin voluntad propia y en medio de Múnich, no parece verosímil, sino marcada por muchas casualidades. 
probabilidad de recibir ayuda de múltiples desconocidos en una sociedad dictatorial. Aunque sí hubo resistencia y personas que ayudaron a las víctimas, esta combinación que se da en la novela parece ser demasiado hipotética. La asimetría entre el verdugo español que hasta el día de hoy no ha cambiado de opinión y el gran número de alemanes buenos hace que el texto pierda complejidad..$^{28}$ En una novela en la que uno de los temas es el Holocausto, este factor puede diluir la cuestión crítica de la culpa alemana, equiparándola con las circunstancias españolas — que en este caso incluso parecen ser peores. No se debe olvidar que Naranjas de sangre, en primer lugar, se dirige al público en Alemania, y por eso existe el riesgo de banalizar el pasado de este país. ${ }^{29}$

Un motivo dominante en la novela es el silencio y el consecuente acuerdo familiar para mantener en silencio el pasado conflictivo. ${ }^{30}$ Funciona como metonimia del consenso colectivo, remitiendo al así llamado «pacto del silencio». El campo semántico de «silencio» domina toda la narración..$^{31}$ La fotografía, por su parte, es la metáfora de un pasado latente. No hace ruido, pero contiene informaciones e historias que esperan ser descubiertas: al darse cuenta de la similitud entre la fotografía de su padre de cuando era soldado de la División Azul y la del tío Hans en la Wehrmacht, Maite se embarca en un proceso de recuperación del pasado de su familia y de España. De este modo, la estancia en otro país inicia un cambio fundamental en la personalidad de la protagonista. De acuerdo con Levy \& Sznaider $(2002,103)$ podemos considerar este proceso como

28 El especial énfasis dado al pasado español se hace visible al comparar entre el número de menciones que hay de «Mauthausen» (8), «Dachau» (5), «campo de concentración» (5) y «Hitler» (30), y entre las que se hacen de «Guardia Civil» (59) y «Franco» (48).

29 Tal como señala Andrea Bies (2017, 141 y s.), la novela contemporánea alemana que trata de España frecuentemente tematiza los conflictos de memoria en este país. En mi opinión, existe cierto riesgo de que las novelas no tomen en consideración el problemático pasado alemán, lo cual se debería comprobar en cada caso particular.

30 Leopoldo Domínguez $(2019,79)$ señala que la novela de Boos remite al así llamado «pacto del silencio» en España y menciona la novela del escritor español Ignacio Martínez de Pisón, Dientes de leche (2009), como obra comparable en cuanto a trama y a personajes transnacionales (Domínguez 2019, 75). Sin embargo, no analiza ni la perspectiva transnacional ni la memoria del Holocausto en Naranjas de sangre.

31 En el original alemán de la novela, la palabra schweigen/Schweigen, que se puede traducir como «callarse» (schweigen) o como «silencio» (Schweigen), aparece 49 veces (Boos 2018). 
elemento de la memoria cosmopolita. Según estos autores, la autoidentificación con la historia del Otro puede ayudar a las personas a desarrollar una perspectiva crítica hacia su propia historia.

Al final de la obra, la exhumación del padre de Antonio de la fosa común se entrecruza con la muerte del padre de Maite (Boos 2017a,354-357). Ella regresa a casa después de una ausencia de muchos años. La defunción del padre da paso a la voz de la madre, que por primera vez habla de su pasado traumático y silenciado (Boos 2017a, 361). Con la muerte de las antiguas élites, personificadas por el padre, las víctimas podrán, por primera vez, hablar por sí mismas y ser escuchadas. De este modo, la novela implica que ahora, en la actualidad del siglo xxi, es el momento adecuado para prestar atención a las víctimas y volver a hablar sobre el pasado. Al descubrir que la parte materna de su familia fue asesinada durante la Guerra Civil, Maite se da cuenta de que ella misma pertenece a una familia con víctimas y victimarios. Sin embargo, eso no la lleva a reconciliarse con su padre muerto. En las últimas líneas de la novela, Maite se vuelve narradora en primera persona al despedirse del cuerpo de su padre: «Le meto la foto del partisano asesinado en el bolsillo del pecho. Esta deuda debe ir con él. Debe acompañarlo [...]. Dejo caer un guijarro y un poco de tierra de la fosa común en su cuello. Le picará» (Boos 2017a, 375). ${ }^{32}$ Con ello la protagonista asume una nueva función, y, a partir de este momento, dominará el discurso, dando así comienzo a una futura restitución de las víctimas. En un acto simbólico, Maite le echa al muerto una piedrecita de la fosa común y le mete la foto de un partisano asesinado en el bolsillo, subrayando con ello que la muerte del perpetrador no le libera de su culpa y que sus crímenes no han prescrito («esta deuda debe ir con él», «le picará»). La foto se vuelve testigo de la muerte del partisano y de todo lo que nunca se dijo, pero que resonará para interrumpir la paz de los muertos. Las fronteras ideológicas que marcan las líneas entre los buenos y los malos siguen vigentes, porque una vida en común no será posible.

32 «Ich stecke das Bild des ermordeten Partisanen in seine Brusttasche. Diese Schuld muss er mitnehmen. Sie soll ihn begleiten [...]. Ich lasse einen Kiesel und etwas Erde aus dem Massengrab in seinen Kragen fallen. Es soll ihn kratzen» (Boos 2018, 407). 


\section{Memorias insulares: Archipel (Archipiélago)}

El título de la novela de Inger-Maria Mahlke, Archipiélago, se puede entender de modo geográfico, pues remite a las Islas Canarias, donde se desarrollará la trama de la historia. Estas islas están aisladas, en el sentido de que tienen una posición periférica. No obstante, las islas son el punto de encuentro para el comercio, el turismo y la política globales. Esto nos posibilita interpretar el título en sentido metafórico, aplicando el concepto de «isla» desarrollado por Ette a la novela de Mahlke para mostrar cómo crea un conjunto de memorias que se pueden calificar como insulares: se entrelazan a múltiples niveles, pero se definen por su perspectiva específica.

De manera similar a la novela de Boos, al texto de Archipiélago le precede una lista de los personajes que tiene cierto parecido con un árbol genealógico. Llama la atención que la cronología empiece en orden invertido, con las generaciones más jóvenes. Se omiten las ramas que normalmente sirven de conexión para dar un orden. Por un lado, esta parte del libro sirve de orientación, pero, por otro, ya se deja entrever que los lectores están obligados a participar activamente en la construcción de sentido, pues ellos mismos tendrán que crear y entender los vínculos existentes entre los personajes. La falta de conexión y orden deconstruye la linealidad y cronología implicadas generalmente en un árbol genealógico. Se hace patente que la historia se produce a partir del presente y que se trata de un proceso continuo interminable.

La novela concluye con un glosario que se dirige a los lectores alemanes y en el que se recopilan las expresiones castellanas que han aparecido a lo largo de la novela junto a su traducción, y donde se explican el contexto histórico o las particularidades tinerfeñas (Mahlke 2018, 425-429). El glosario parece tener una función didáctica: de modo similar a Boos, Mahlke sitúa su novela en un contexto sociohistórico concreto y ayuda a los lectores a informarse sobre lo que acaban de leer. No obstante, Mahlke, a diferencia de Boos, no menciona las fuentes consultadas. ${ }^{33}$ El glosario

33 Aunque no se mencione ninguna en el glosario de la novela, se puede suponer que Los salones de Fyffes, del cineasta tinerfeño David Baute (2005), es una de las fuentes consultadas. Este documen- 
clarifica las ambigüedades del texto literario, como se puede observar en el siguiente ejemplo:

Fyffes: nombre oficial, Prisión militar Costa Sur, [...]; campo de concentración fascista en Santa Cruz. Por la noche se llevaban a cabo las denominadas sacas: se leían las nóminas para, a continuación, ejecutar a los presos en Las Cañadas, en el Barranco Santos y en otros lugares. La mayoría fueron fusilados o llevados a mar abierto en barcos y arrojados por la borda. Hasta el día de hoy se desconoce el número exacto de las víctimas. ${ }^{34}$

El glosario está escrito en un tono científico que retoma los elementos del texto ficcional para relacionarlos con el contexto histórico. Mientras que el texto literario no siempre hace referencia a la violencia explícitamente, el glosario sí lo hace («ejecutar», «fusilados», «arrojados»). Estos hechos se describen usando el pretérito imperfecto, pero la última frase crea un vínculo directo con el presente («hasta el día de hoy»), mostrando que aún quedan vacíos no resueltos. Las víctimas siguen siendo anónimas. Al mencionar el Fyffes, una exportadora de plátanos irlandesa, se critica implícitamente la manera en la que actúa el comercio global, relegando la política a un segundo plano por detrás del dinero..$^{35}$ Esta crítica puede equipararse a los actuales debates sobre la ética de comerciar con países dictatoriales.

En contraste con el glosario, el epígrafe al inicio de la novela crea un vínculo con la escritora y su propia historia familiar: «Ya voy llegando a mi casa, donde muero y vivo yo. Las paredes me conocen, pero los bienes de mi vida no. (sagt meine Abuela)» (Mahlke 2018, 5). El epígrafe se caracteriza

tal muestra cómo los hangares de la exportadora de plátanos fueron transformados en un campo de reclusión. Las definiciones que se ofrecen en el glosario de Archipiélago y el hecho de que el apellido Baute es dominante en la novela son dos indicios que apoyan esta hipótesis.

34 «Fyffes: offiziell Prisión militar Costa Sur [...]; faschistisches Konzentrationslager in Santa Cruz [...]. Nachts fanden sogenannte Sacas statt (von sacar: herausholen): Namenslisten wurden verlesen und die Häftlinge daraufhin in Las Cañadas, im Barranco Santos und an anderen Orten ermordet. Die meisten wurden erschossen oder mit Schiffen aufs offene Meer hinausgefahren und über Bord geworfen. Die genaue Anzahl der Opfer steht bis heute nicht fest» (Mahlke 2018, 427).

35 También se ofrece un ejemplo de los años treinta, en los que las compañías enviaban sus productos al mercado alemán sin importarles que el gobierno del país fuera nacionalsocialista (Mahlke 2018, 375). 
por el code-switching empleado entre el español y el alemán («sagt meine Abuela», o sea, «dice mi abuela»). La alusión a la oralidad, la rima (entre «yo» $\mathrm{y}$ «no») y la mención a la abuela permiten considerar el epígrafe como un lema que se transmite a través de las generaciones. Con esto también se remite a la memoria comunicativa, en este caso transnacional, que la abuela española pasará a su nieta alemana. Al igual que en la novela de Boos, aparece el motivo de la casa, que puede entenderse tanto como la casa natal o como el país en el que alguien ha nacido. El sentimiento de pertenencia a un lugar concreto en la vida y en la muerte contrasta con la diversidad lingüística del fragmento. El concepto de identidad transmitido aquí puede interpretarse mediante la metáfora de la isla: la identidad vacila entre lo singular y lo entrecruzado, entre el origen y el movimiento. La mención de la muerte antes de la vida («muero y vivo») invierte el orden cronológico y ya es un indicio para la cronología de la narración que sigue. Esta empieza en 2015 y recorre casi un siglo entero hasta concluir en el año 1919. La estructura acrónica de la narración rompe con la linealidad del tiempo y con la manera de concebir la historia como una evolución constante y progresiva. Cada capítulo del texto narrativo lleva un año como título (p. ej., «2015», «1975», «1936», etc.) y se divide en fragmentos de unas pocas páginas. En cada fragmento, el narrador extra- $y$ heterodiegético focaliza los pensamientos de uno de los personajes, creando así una visión íntima de sus temores y sueños en el respectivo año. Como el narrador nunca asume una posición autorial, siempre transmite de forma fiel la complejidad psicológica de los personajes. Conforme a Rothberg, esta estructuración narrativa permite crear una visión multidireccional del pasado. No obstante, el texto se niega a dar explicaciones y el lector se ve obligado a hacer su propia evaluación de lo que se cuenta y de lo que no se cuenta. De esta manera, la novela se despide de los llamados «metarrelatos», creando así una perspectiva multifocal.

Archipiélago es un retrato de tres familias que viven en Tenerife: las familias Bernadotte, Baute y Morales. Mientras que los Bernadotte pertenecen a la clase más alta con dinero y propiedades heredados, los Baute son de clase media. La familia Morales representa la clase baja de las empleadas domésticas. A finales del siglo xx, estas tres familias se entrelazan con el matrimonio de Felipe Bernadotte y Ana Baute, que tienen una hija, Rosa. 
A lo largo de la narración, los lectores acompañan a los distintos miembros de las tres familias, así como a sus antepasados. Los grandes sucesos y procesos históricos, como la Guerra Civil, la Segunda Guerra Mundial y la globalización, influyen en la vida de los protagonistas de distintas formas.

El personaje central a lo largo de estos años es Julio Baute, el abuelo de Rosa, nacido en el año 1919, es decir, al final de la narración. Al inicio de la misma, se presenta al personaje como un anciano de 94 años que está viviendo en un asilo y que no parece tener una buena relación con su familia: “¿Por qué nos odia el abuelo?”, preguntó Rosa un día. "El abuelo no nos odia." La voz de Ana, severa». ${ }^{36}$ Esta cita ejemplifica la falta de entendimiento mutuo entre las generaciones. Ana no quiere saber por qué su hija tiene la impresión de ser odiada. Tampoco intenta explicar el comportamiento frío del abuelo. No hace más que contradecir a su hija y mostrarse severa, con una total falta de empatía. Las frases cortas - la última incluso es elíptica- subrayan el poco espacio que ocupan los sentimientos y el verdadero diálogo dentro de la familia. Igual que en la novela de Boos, aquí la familia se puede interpretar como un pars pro toto de la sociedad española. La comunicación fracasada apunta hacia los enfrentamientos entre los distintos grupos sociales y la relación conflictiva con el pasado histórico.

No es hasta que Julio empieza a charlar con Amalia, una de las habitantes del asilo a la que le han diagnosticado demencia senil, que empezamos a sospechar lo que podría ser la causa de su comportamiento distante. Cada vez que Amalia se encuentra con Julio, ella le pregunta por un tal Mario:

- ¿Se llama usted Mario?

Julio Baute vuelve a bajar la mano.

-No — dice, percibiendo lástima en su voz.

-Yo conocía a un Mario — dice Amalia González Herrera-. Pero, si lo pienso

bien... - Hace una pausa-. Creo que tuvo un accidente con el camión.

-Lo lamento. ¿Se quiere sentar?

$[\ldots]$

36 Todas las traducciones de la novela de Mahlke son mías. Texto original: «"Warum hasst Opa uns?”, hat Rosa irgendwann gefragt. “Opa hasst uns nicht.” Anas Stimme streng» (Mahlke 2018, 30). 
—Era falangista. El azul le quedaba bien.

—Disculpe, quiero ver esto — dice Julio Baute y toma el control remoto.

Menú aparece en la pantalla, sus dedos no parecen responder, Salida, por fin dan con el botón.

Julio sube el volumen. ${ }^{37}$

La mención del color azul y de la afiliación política de Mario marcan un momento decisivo. Julio reacciona intentando controlar sus emociones («toma el control remoto») y huyendo («Salida», «sube el volumen»). Las palabras de la mujer desencadenan una avalancha de recuerdos que Julio había reprimido y cuyo repentino surgimiento pone en riesgo el control de sus emociones. Aquí se pueden observar dos maneras distintas de tratar la memoria. Por un lado, por su demencia, Amalia comparte informaciones privadas sin tener en cuenta la reacción de sus interlocutores, estando así condenada a revivir los momentos del pasado continuamente. Por otro lado, Julio intenta a toda costa controlar sus emociones y recuerdos, reprimiéndolos y, con ello, manteniendo el pasado a distancia. No obstante, hemos visto ya que esto complica la comunicación con su familia. En cierto modo, Julio también está condenado a sentir los efectos del pasado en su vida actual. El lector empieza a percibir el pasado problemático del protagonista, que poco a poco vuelve a aflorar. Las heridas del pasado siguen complicando el diálogo de Julio con su familia. No será hasta casi 300 páginas más adelante que, después de un viaje de ochenta años en el pasado - regresando al año 1936-, los lectores descubrirán que Julio fue encarcelado y llevado a lo que se llama el Guano:

Para algunos hay sentencias en el Guano, para algunos hay cursos, para otros solamente la voz. No es la misma cada noche, una viene de Cataluña, otra de

37 «"Heißen Sie Mario?” Julio Baute lässt die Hand wieder sinken. “Nein”, sagt er und hört Bedauern in seiner Stimme. "Ich kannte mal einen Mario”, sagt Amalia González Herrera. "Aber wenn ich recht überlege", sie macht eine Pause, "ich glaube, er ist mit dem Lastwagen verunglückt." "Das tut mir leid. Möchten Sie sich setzen?” [...] “Er war Falangist. Blau stand ihm gut.” "Entschuldigung, ich möchte das sehen”, sagt Julio Baute und nimmt die Fernbedienung. Menü erscheint auf dem Bildschirm, seine Finger wollen nicht richtig, Exit, endlich haben sie die Taste. Er stellt den Ton lauter» (Mahlke 2018, 94). 
Andalucía, pero la mayoría de las veces es de aquí. La voz lee de forma lenta y siempre idéntica, como si quisiera hacerle justicia a cada nombre, es floja y aun así se escucha hasta en el rincón más alejado. Los que rezan, lo hacen en silencio, nada más que el sonido suave de labios juntándose apresurados. [...] «Hemorragias internas», escribe el médico meticulosamente al día siguiente, no sin antes quitar la tinta excedente de la pluma, para no dejar manchas en el formulario, meticuloso y limpio. «Causa de la muerte: hemorragias internas». ${ }^{8}$

El motivo de la voz domina este pasaje. En vez de gritos violentos, predominan los sonidos tenues. La sintaxis paralela crea un ritmo constante que subraya el flujo de los presos que entran en el Guano. La multitud de nombres que proclama la voz contrasta con el hecho de que el narrador no los nombra. De este modo, marcan un vacío, metáfora del anonimato y de la incapacidad de determinar un número exacto de víctimas. Mientras que ciertos detalles se describen minuciosamente, hay cosas que son silenciadas y no se cuentan. Por ejemplo, la «tinta», que se asemeja a la sangre. El movimiento cuidadoso de la pluma contrasta con el trato brutal que probablemente causó las «hemorragias internas» del muerto — pero esta parte no se cuenta y el muerto no tiene ni nombre ni presencia física. La cita ejemplifica el modo en el que Archipiélago trata la violencia, que la mayoría de las veces aparece de manera implícita. Cuando al final la violencia ya aparece de manera explícita, el lenguaje del ámbito médico le da un barniz científico, crea una distancia que alude a la falta de empatía que predomina en el Guano.

En relación con la historia española, el texto remite a distintos temas que hoy día siguen siendo centrales, como, por ejemplo, los niños robados

38 «ür einige im Guano gibt es Urteile, für einige Kurse, für andere nur die Stimme. Es ist nicht jede Nacht die gleiche, eine stammt aus Cataluña, eine aus Andalucía, meistens aber ist sie von hier. Die Stimme liest langsam und gleichmäßig, als wolle sie jedem Namen gerecht werden, leise und ist doch bis in den hintersten Winkel zu verstehen. Diejenigen, die beten, tun es still, nur die weichen Laute hastig aufeinandertreffender Lippen. [...] Innere Blutungen, schreibt der Arzt sehr ordentlich am nächsten Tag, streicht vorher die überschüssige Tinte von der Feder ab, um keine Flecken auf dem Formular zu hinterlassen, ordentlich und sauber. Todesursache: innere Blutungen»(Mahlke 2018, 371 y s.). 
por la Iglesia ${ }^{39}$ o las exhumaciones ${ }^{40}$ (Mahlke 2018, 135 y 324). No obstante, como muchas veces solamente se trata de alusiones, es probable que los lectores - sobre todo si son alemanes - no siempre las vayan a percibir. La gran cantidad de datos y la inversión del orden cronológico hacen que se pierda la atención. Otro aspecto problemático es que, por un lado, en el glosario se explican cosas tan básicas como quién es Franco (Mahlke 2018, 427), pero, por otro, se mencionan tantos detalles sobre la historia española que la novela a veces resulta algo confusa. Dudo, por ejemplo, que todos vayan a entender el doble sentido de un título como «El carnaval de 1981», que se refiere al 23-F (Mahlke 2018, 203).

A lo largo de la novela, los vínculos entre el pasado alemán y español surgen con la mención del buque Robert Ley (Mahlke 2018, 296), que pasó por Tenerife en 1939 con el programa nazi Kraft durch Freude (Kludas 1999, 134-136). ${ }^{41}$ La novela demuestra que la tendencia alemana a considerar Tenerife como un lugar para pasar unas vacaciones agradables — sin preocuparse de la sociedad o la ecología - es una constante histórica que continúa hasta el día de hoy. Archipiélago logra mostrar otra imagen de la isla. Sin embargo, no se mencionan los campos de concentración alemanes en los que también se mataba a españoles. Esta novela hace muchas menos alusiones a la historia compartida de Alemania y España que la de Boos. No obstante, la novela contribuye a cambiar la percepción superficial sobre Tenerife, mostrando a los lectores alemanes un mundo narrado diferenciado y complejo. Empleando los términos de Levy y Sznaider (2002, 103), se puede decir que con la novela se tiene en cuenta la historia ajena.

A primera vista, la novela da la impresión de ser un ejemplo de reconciliación colectiva, por el matrimonio entre la familia Baute y Bernadotte. Felipe, el hijo del militar, es un historiador con una visión crítica sobre su legado familiar, mientras que Ana es diputada del Partido Popular a pe-

39 Gimber \& Rodríguez $(2012,15)$ señalan que tanto en la RDA como en España se siguió una política represiva en lo que se refiere a las adopciones forzadas. En el artículo se muestra cómo las novelas y películas que retoman estos hechos forman parte de los debates nacionales, aportando a estos una perspectiva singular y empática (Gimber \& Rodríguez 2012, 20-26).

40 Para un análisis de las diversas repercusiones actuales de las exhumaciones de fosas comunes, véase Ferrándiz (2014).

41 Véase el artículo de Olaya (2019) sobre la presencia de la Marina de Guerra alemana en Canarias durante la Segunda Guerra Mundial. 
sar del pasado traumático de su padre Julio. El mensaje implícito es que las opiniones políticas se pueden cambiar. Aunque nadie está obligado a seguir la afiliación política de su familia, es imposible negar que el pasado histórico influye hasta hoy día en la postura política de los españoles. ${ }^{42}$ La decisión de ambos personajes de romper con su pasado histórico desemboca en conflictos familiares y, en el mundo narrado, la reconciliación fracasa: Felipe se vuelve alcohólico y Ana se ve involucrada en un caso de corrupción (Mahlke 2018, 56). De este modo, los dos personajes, con sus diferentes intereses, representan la colaboración fracasada de la historiografía con la política. En Archipiélago, la corrupción disminuye considerablemente el poder de la política (Ana), mientras que la historiografía crítica es condenada a la irrelevancia (Felipe). El tercer grupo es el de las empleadas domésticas, que representan la clase social más baja de la sociedad. Ellas nunca lograrán salir de su situación precaria y no son incluidas en ningún proceso de reconciliación. Con estos ejemplos, Archipiélago muestra el peligro que trae consigo la falta de comunicación, remitiendo así a la sociedad extraliteraria.

Archipiélago se lee como una invitación a escuchar lo que nos cuentan los abuelos y últimos sobrevivientes. El texto literario puede dar vida al pasado y hacer que veamos lo jóvenes que han sido nuestros antepasados - con planes para una vida entera. Nos ayuda a sentir empatía con las víctimas del pasado. También podemos aprender mucho al prestar atención al modo en el que se manifiesta la demencia, como se ha visto en el personaje de Amalia: con ella vuelven a luz los momentos más impactantes y los detalles silenciados del pasado. En cambio, una sociedad en la que se mantienen los recuerdos bajo control total y se reprimen los momentos dolorosos (Julio), no llegará a hacer las paces con el pasado. La manera especial de Archipiélago de contar la historia al revés logra aislar distintos momentos de la vida de cada personaje. La vida es un archipiélago de muchas islas que normalmente intentamos conectar entre sí para producir una visión homogénea del pasado. Entendido de este modo, el relato li-

42 Este conflicto sobre la valoración del pasado franquista se ha podido ver con los debates entorno a la Ley de memoria histórica de 2007 (Bernecker 2008) y recientemente con los debates acerca de la exhumación de Francisco Franco del Valle de los Caídos (García de Blas \& Junquera 2019). 
neal y homogéneo siempre se crea a posteriori. El texto literario nos obliga a observar cada isla en sí misma, aceptando los fragmentos y las cesuras que no encajan en la linealidad. La combinación de los detalles íntimos presentados en el texto literario y del lenguaje historiográfico y científico empleado en el glosario logra transmitir una visión compleja del pasado.

\section{Conclusiones}

En los últimos años, en las investigaciones sobre la memoria han surgido conceptos que intentan definir el efecto que tiene la globalización en los procesos relacionados con esta: tres ejemplos de ello son la memoria cosmopolita (Levy \& Sznaider), la memoria multidireccional (Rothberg) y la memoria transareal (Ette). Los cuatro teóricos concuerdan en que este nuevo marco de la memoria es una oportunidad para fomentar la solidaridad con las historias ajenas. En el espacio europeo actual, en el que se acaban de celebrar los grandes aniversarios históricos, esta perspectiva multifocal es imprescindible para reevaluar el pasado histórico y crear la base para un futuro común.

Las obras ficcionales contribuyen a estos debates, ya que influyen en nuestro imaginario colectivo. Siguiendo esta premisa, en el presente artículo se ha analizado qué imagen de la Guerra Civil, la Segunda Guerra Mundial y el franquismo transmiten las novelas alemanas contemporáneas Naranjas de sangre (Boos) y Archipiélago (Mahlke), y de qué manera contribuyen a la perspectiva de una memoria cosmopolita, multidireccional o transareal. ${ }^{43}$ Ambas novelas logran dejar atrás una perspectiva nacional con sus narraciones multifocales, con personajes con biografías transnacionales y con la tematización de la historia compartida europea.

43 Para investigaciones futuras resultaría interesante analizar un fenómeno nuevo del género policíaco, que es la escritura colaborativa transnacional. La trilogía policíaca de las dos escritoras Rosa Ribas, española, y Sabine Hofmann, alemana, se sitúa en la Barcelona de los años cincuenta. Cada escritora redactó su contribución en su respectiva lengua, lo que llevó a la publicación casi simultánea de las novelas tanto en español (Ribas \& Hofmann 2013, 2016, 2017a) como en alemán (Ribas \& Hofmann 2014a, 2017b, 2018). Ribas y Hofmann han publicado un diario donde documentan este peculiar proceso de escritura transnacional (Ribas \& Hofmann 2014b). 
De este modo, las novelas impulsan la empatía con las víctimas y son un ejemplo de que hay relatos más allá de lo nacional.

$\mathrm{Al}$ deconstruir la linealidad, ambas novelas se despiden de la visión de la historia como un progreso continuo, tal y como se puede observar en su estructura temporal: mientras las frecuentes analepsis en Naranjas de sangre hacen que el pasado se entrelace con el presente y se cree una visión íntima de las emociones de los personajes, Archipiélago cuenta la historia al revés, eliminando toda posible continuidad, por no ser un relato homogéneo.

Con los árboles genealógicos, las novelas retoman elementos del género de la saga familiar. Los personajes representan distintos grupos sociales y su memoria comunicativa, mostrando así que la memoria colectiva se forma mediante los distintos recuerdos individuales. No obstante, ambos textos deconstruyen la genealogía implicada habitualmente en una saga familiar: Naranjas de sangre se centra en la reconciliación del presente con el pasado, mientras que Archipiélago opta por la fragmentación de la historia.

A nivel paratextual, las novelas añaden información sobre el contexto histórico español y alemán, señalando los vínculos entre ambos países. Archipiélago lo hace en forma de glosario; Naranjas de sangre mencionando fuentes historiográficas en distintas lenguas (inglés, alemán, español). Esta última aboga por un diálogo historiográfico internacional y multilingüe. Ambas novelas ayudan al lector a informarse sobre las alusiones hechas en el texto y se posicionan en un contexto sociohistórico concreto. De este modo, los lectores alemanes tienen la posibilidad de aprender más sobre las dimensiones europeas de su propia historia y de sentir empatía con las víctimas españolas.

Ambas obras remiten a los vínculos históricos entre la Alemania nazi y la España de Franco, mostrando que los nacionalsocialistas asesinaron a españoles en los campos de concentración (Boos) y que la controvertida mirada turística de los alemanes hacia España tiene una continuidad histórica (Mahlke). A través de las historias vividas por los personajes, las novelas contribuyen a formar una memoria transareal que no se limita únicamente a un marco nacional. No obstante, se ha podido mostrar que la mayoría de los personajes que representan a los verdugos son unidi- 
mensionales y estereotipados. De este modo, corren el riesgo de crear la imagen de un mal ajeno y ahistórico que es separado por nuevos límites de los buenos.

En cuanto a su valoración de los actuales debates de memoria histórica en España, la novela de Boos claramente se posiciona a favor de las víctimas y de la Asociación para la Recuperación de la Memoria. En el texto de Mahlke la postura política es más ambigua y la focalización interna de personajes de distintos bandos políticos evita que la historia se limite a un mundo en blanco y negro. No obstante, evoca un presente similar, en el que la reconciliación fracasa a causa de la falta de comunicación tanto entre las generaciones como entre la política (Ana) y la historiografía (Felipe). Otro motivo literario dominante que apunta hacia esta interpretación y que aparece en ambas novelas es el silencio, que remite al pacto del silencio, implicando que sigue vigente en la sociedad española. En la novela de Boos, no será hasta la muerte de las antiguas élites (el padre) que las víctimas (la madre) y las generaciones jóvenes (Maite) obtengan su propia voz. La novela substituye las fronteras nacionales por fronteras ideológicas con las que una verdadera convivencia no parece ser posible.

Además de estas fronteras, existen límites sociales que se ponen de manifiesto a través de las empleadas domésticas marginalizadas. Por lo general no cuentan su versión de la historia y nadie las quiere escuchar. En Naranjas de sangre, nunca se focaliza la empleada, lo cual crea un vacío que no se llena hasta el final. Las empleadas no quedan integradas en el consenso, por lo que no asumen ningún papel en la creación de una memoria cosmopolita. Mientras que las afiliaciones y el poder político pueden cambiar (Mahlke), los grupos más pobres nunca llegan a adquirir otro estatus social. Hasta que esto no cambie, una verdadera reconciliación con el pasado y entre los grupos sociales fracasará. Con este mensaje implícito, se delega la responsabilidad a los lectores. Se trata de entablar un diálogo que no se limite a lo nacional, sino que también considere los límites sociales, entendiendo que, para cultivar la memoria colectiva, es imprescindible tener en cuenta la individual.

Asimismo, las novelas demuestran que lo importante es mirar hacia el pasado desde una perspectiva que tome en consideración los vínculos entre los distintos países europeos. Por lo menos a nivel binacional, entre 
Alemania y España, podemos concluir que las novelas logran narrar una historia compartida. No obstante, la novela de Boos tiende a reproducir ciertos estereotipos atribuidos a España (las naranjas, Francisco contra Antonio). Aun así, fue traducida al español y al catalán y recibida con interés en España aunque no fuese premiada allí. En cuanto se publique la novela de Mahlke en España, resultaría interesante analizar su recepción en los medios españoles y si se producen debates sobre su manera de retratar el pasado histórico.

Por último, las novelas de Boos y Mahlke sugieren que el pasado solo puede ser entendido a través del diálogo entre la ficción y la historiografía. Mientras que la última se caracteriza por crear relatos lineales y por hacer referencia a los hechos explícitamente, no siempre logra dar vida al pasado. Es precisamente aquí donde la narración ficcional desempeña un papel imprescindible a la hora de crear visiones íntimas del pasado y encontrar un lenguaje que transmita la compleja violencia traumatizante a través de metáforas. La vida de los personajes ficcionales sirve como elemento de identificación y permite a los lectores sentir empatía con personas con las que no necesariamente empatizarían en la realidad. Entendido de este modo, el texto literario puede contribuir considerablemente a la creación de una memoria cosmopolita, multidireccional o transareal, ya que hace accesible y comprensible la historia del Otro. La literatura es capaz de influir en el imaginario colectivo y en la percepción de la historia europea compartida que va más allá de un punto de vista nacional. ${ }^{44}$

\section{Bibliografía}

Alianza Internacional para la Memoria del Holocausto. 2000. «Declaración del Foro Internacional de Estocolmo sobre el Holocausto». https://www. holocaustremembrance.com/index.php/es/node/17. [Consulta: 7 diciembre 2019.]

Aragoneses, Alfons. 2017. «Legal Silences and the Memory of Francoism in Spain». Dentro Uladzislau Belavusau y Aleksandra Gliszczynska-Grabias, ed., Law and Memory. Towards Legal Governance of History, 175-193. Cambridge: Cambridge University Press.

Arraéz, José Luis. 2017. «Les voix/es de la mémoire dans Pas pleurer de Lydie Salvayre». French Cultural Studies 28 (2): 186-197. doi: https://doi.org/10.1177/0957155817695495.

44 Agradezco a Sonia López su valiosa ayuda lingüística y estilística en el proceso de escritura. 
Asholt, Wolfgang; Reinecke, Rüdiger, y Susanne Schlünder, ed. 2009. Der Spanische Bürgerkrieg in der DDR. Strategien intermedialer Erinnerungsbildung. Fráncfort del Meno: Vervuert.

Assmann, Aleida, y Sebastian Conrad, ed. 2010. Memory in a Global Age. Basingstoke: Palgrave Macmillan.

Assmann, Jan. 1988. «Kollektives Gedächtnis und kulturelle Identität». Dentro Jan Assmann y Tonio Hölscher, ed., Kultur und Gedächtnis, 9-19. Fráncfort del Meno: Suhrkamp.

Auweiler, Julia. 2019. «Verena Boos’ Blutorangen (2015) - ein deutscher Beitrag zur literatura de la memoria?». Quaderns de Filologia: Estudis Literaris 24: 253-269. doi: http://dx.doi.org/10.7203/qdfed.24.16343.

Bannasch, Bettina, y Christiane Holm, ed. 2005. Erinnern und Erzählen. Der Spanische Bürgerkrieg in der deutschen und spanischen Literatur und in den Bildmedien. Tubinga: Gunter Narr.

Baute, David, dir. 2005. Los salones de Fyffes. La memoria silenciada, documental. Santa Cruz de Tenerife: Televisión Canaria / Tinglado Film.

Bernecker, Walther L. 2008. «Die verspätete Aufarbeitung der Vergangenheit: Spanien zwischen Amnesie und politisch-ideologischer Instrumentalisierung». Peripherie 28 (109): 174-195.

Bies, Andrea. 2017. «Die Spanien-Episode in Hans-Ulrich Treichels Grunewaldsee». Revista de Filología Alemana 25: 131-144. doi: http://dx.doi.org/10.5209/RFAL.56371. Boos, Verena. 2018 [2015]. Blutorangen. Berlín: Aufbau.

—. 2017a. Naranjas de sangre, traducción de Francisco García Lorenzana. Barcelona: Plataforma.

- 2017b. Taronges de sang, traducción de Ramon Montón. Alzira: Bromera.

Bosshard, Marco Thomas. 2016. «Nationalsozialismus und Genozid in der spanischen Gegenwartsliteratur». Romanische Studien 4: 287-303.

Brenneis, Sara J. 2018. Spaniards in Mauthausen. Representations of a Nazi Concentration Camp, 1940-2015. Toronto: University of Toronto Press.

Carracedo, Almudena, y Robert Bahar, dir. 2018. El silencio de otros, documental. Madrid / Nueva York: Lucernam Films / Semilla Verde Productions.

Deutscher Buchpreis. Sin fecha. «Deutscher Buchpreis 2018. Preisträger, Shortlist, Longlist und die Jury des Deutschen Buchpreises von 2018». https://www.deutscherbuchpreis.de/archiv/jahr/2018/. [Consulta: 21 mayo 2020.]

Dückers, Tanja. 2003. Himmelskörper. Berlín: Aufbau.

Erll, Astrid. 2017. Kollektives Gedächtnis und Erinnerungskulturen. Eine Einführung. Stuttgart: J. B. Metzler.

Ette, Ottmar. 2012. «Worldwide: Living in Transarchipelagic Worlds». Dentro Ottmar Ette y Gesine Müller, ed., Worldwide. Archipels de la mondialisation. Archipiélagos de la globalización, 21-59. Madrid / Fráncfort del Meno: Iberoamericana/Vervuert.

- 2010. ZusammenLebensWissen. List, Last und Lust literarischer Konvivenz im globalen Maßstab. Berlín: Kulturverlag Kadmos. 
Ferrándiz, Francisco. 2014. El pasado bajo tierra. Exhumaciones contemporáneas de la Guerra Civil. Barcelona: Anthropos.

Fiedler, Matthias. 2006. «German Crossroads: Visions of the Past in German Cinema after Reunification». Dentro Anne Fuchs, Mary Cosgrove y Georg Grote, ed., German Memory Contests: The Quest for Identity in Literature, Film, and Discourse since 1990, 127-146. Rochester/Woodbridge: Camden House.

Forkel, Robert. 2019. «Literarisches Geschichtserzählen über die Zeit des Nationalsozialismus». Dentro Daniel Fulda y Stephan Jaeger, ed., Romanhaftes erzählen von Geschichte. Vergegenwärtigte Vergangenheiten im beginnenden 21. Jahrhundert, 205-228. Berlín: De Gruyter.

Fransecky, Tanja von. 2014. Flucht von Juden aus Deportationszügen in Frankreich, Belgien und den Niederlanden. Berlín: Metropol.

García de Blas, Elsa, y Natalia Junquera. 2019. «El PP se pone de perfil ante la exhumación de Franco y Cs le resta importancia».El Pais, 24 sept. https://elpais.com/ politica/2019/o9/23/actualidad/1569238701_053316.html. [Consulta: 29 mayo 2020.]

Genette, Gérard. 1987. Seuils. París: Seuil.

-1972. Figures III. París: Seuil.

Gimber, Arno, y José Manuel Rodríguez. 2012. «Niños robados y adopciones forzadas. Su presencia en la memoria colectiva en España y Alemania». Dentro Werner Altmann, Rosamna Pardellas Velay y Ursula Vences, ed., Historia hispánica. Su presencia y (re) presentación en Alemania, 15-28. Berlín: Walter Frey.

Goethe-Institut Barcelona. 2017. «3 Fragen an Verena Boos», vídeo. https://www. youtube.com/watch?v=cs2HfkvrooE. [Consulta: 23 mayo 2020.]

Gómez López-Quiñones, Antonio. 2006. La guerra persistente. Memoria, violencia y utopía: representaciones contemporáneas de la Guerra Civil española. Madrid / Fráncfort del Meno: Iberoamericana/Vervuert.

Guixé i Coromines, Jordi, ed. 2016. Past and Power. Public Policies on Memory. Debates, from Global to Local. Barcelona: UB.

Halbwachs, Maurice. 1976. Les cadres sociaux de la mémoire. París / La Haya: Mouton.

Hansen, Hans Lauge. 2015. «Formas globales e historias locales. Influencias transnacionales en la narrativa actual sobre la guerra civil». Dentro Juan Carlos Cruz Suárez, Hans Lauge Hansen y Antolín Sánchez Cuervo, ed., La memoria novelada III. Memoria transnacional y anhelos de justicia, 123-150. Berna: Peter Lang.

Hummel, Eleonora. 2005. Die Fische von Berlin. Gotinga: Steidl.

Jünke, Claudia. 2015. «¿Hacia una memoria transcultural? Reflexiones acerca de la narrativa memorialista española actual». Dentro Juan Carlos Cruz Suárez, Hans Lauge Hansen y Antolín Sánchez Cuervo, ed., La memoria novelada III. Memoria transnacional y anhelos de justicia, 151-166. Berna: Peter Lang.

Kludas, Arnold. 1990. Die Geschichte der deutschen Passagierschiffahrt. Band V. Eine Ära geht zu Ende, 1930 bis 199o. Hamburgo: Ernst Kabel.

Kraume, Lars, dir. 2015. Der Staat gegen Fritz Bauer, película. Berlín: Zero One Film.

La Vanguardia. «Inger-Maria Mahlke obtiene el premio a la mejor novela alemana del año». La Vanguardia, 8 oct. https://www.lavanguardia.com/ 
vida/20181008/452243828343/inger-maria-mahlke-obtiene-el-premio-a-la-mejornovela-alemana-del-ano.html. [Consulta: 24 mayo 2020.]

Levy, Daniel, y Natan Sznaider. 2002. «Memory Unbound. The Holocaust and the Formation of Cosmopolitan Memory». European Journal of Social Theory 5 (1): 87106. doi: https://doi.org/10.1177\%2F1368431002005001002.

Librerío de la Plata. 2017. «Verena Boos presenta "Naranjas de sangre” en el Librerío», vídeo. https://www.youtube.com/watch?v=abrA2lLHGT4. [Consulta: 23 mayo 2020.]

Link, Caroline, dir. 2019. Als Hitler das rosa Kaninchen Stahl, película. Berlín: Sommerhaus Filmproduktion.

Llopart, Frederic. 2018. «Taronges de Sang». Eix Diari, 7 abr. https://www.eixdiari.cat/ opinio/doc/76607/taronges-de-sang.html. [Consulta: 24 mayo 2020.]

Mahlke, Inger-Maria. 2018. Archipel. Reinbek: Rowohlt.

Moreno Juliá, Xavier. 2012. «La División Azul en el contexto de las relaciones entre la España de Franco y la Alemania nazi». Cuadernos de Historia Contemporánea 34: 65-90.

Musolff, Andreas. 2010. Metaphor, Nation and the Holocaust. The Concept of the Body Politic. Nueva York / London: Routledge.

Nopca, Jordi. 2017. «Verena Boos: "Espanya i Alemanya tenen una història de violència compartida." L'escriptora connecta Hitler i Franco a la seva primera novella, Taronges de sang».Ara, 12 jun. https://www.ara.cat/cultura/Espanya-Alemanyahistoria-violencia-compartida_o_1813018725.html. [Consulta: 24 mayo 2020.]

Olaya, Vicente G. 2019. «Banderas nazis en Canarias». El País, 2 oct. https://elpais.com/ cultura/2019/o9/30/actualidad/1569861795-043288.html. [Consulta: 28 mayo 2020.]

Olmos, Ignacio. 2009. «Introducción». Dentro Ignacio Olmos y Nikky Keilholz-Rühle, ed., La cultura de la memoria. La memoria histórica en España y Alemania, 7-11. Madrid / Fráncfort del Meno: Iberoamericana/Vervuert.

Real Academia Española. 2014. «Sabor». Diccionario de la lengua española. https://dle. rae.es/sabor? $\mathrm{m}=$ form. [Consulta: 26 noviembre 2019.]

Ribas, Rosa, y Sabine Hofman. 2013. Don de Lenguas. Madrid: Siruela.

—. 2014a. Das Flüstern der Stadt. Reinbek: Rowohlt.

. 2014b. «Arbeitsjournal zu "Das Flüstern der Stadt”». https://www.rowohlt.de/ news/ribas-hofmann-fluestern-stadt-arbeitsjournal.html. [Consulta: 24 mayo 2020.]

- 2016. El gran frío. Madrid: Siruela.

- 2017a. Azul marino. Madrid: Siruela.

- 2017b. Die große Kälte. Reinbek: Rowohlt.

- 2018. Auf der anderen Seite der Ramblas. Reinbek: Rowohlt.

Ricciarelli, Giulio, dir. 2014. Im Labyrinth des Schweigens, película. Alemania: Universal. Rodríguez Marcos, Javier. 2019. «Antonio Machado en el andén del exilio». El País, 16 feb. https://elpais.com/cultura/2019/02/15/babelia/1550257997-73156o.html. [Consulta: 26 mayo 2020.]

Rowohlt. Sin fecha (a). «Inger-Maria Mahlke». https://www.rowohlt.de/autor/ingermaria-mahlke.html. [Consulta: 10 diciembre 2019.] 
Rowohlt. Sin fecha $(b)$. «Inger-Maria Mahlke: Archipelago». https://www.rowohlt.de/ catalogue/hardcover/inger-maria-mahlke-archipel.html. [Consulta: 23 mayo 2020.]

Rothberg, Michael. 20o9. Multidirectional Memory. Stanford: Stanford University Press.

Salvayre, Lydie. 2014. Pas pleurer. París: Seuil.

Stanišić, Saša. 2019. Herkunft. Múnich: Luchterhand.

Suomi, Iván. 2018. «Una novela sobre la historia de Canarias, premio Deutscher Buchpreis 2018». Tamaimos. Semanario crítico canario, 10 oct. http://www. tamaimos.com/2018/10/10/una-novela-sobre-la-historia-de-canarias-premiodeutscher-buchpreis-2018/. [Consulta: 24 mayo 2020.]

Ramiro Troitiño, David et al., ed. 2020. The EU in the 21st Century. Berlín: Springer.

Teutsch, Katharina. 2015. «Die unwissenden Enkel werden sich wundern». Frankfurter Allgemeine Zeitung, 8 sept.

Verena Boos. «Verena Boss». http://verena-boos.de/english/. [Consulta: 10 diciembre 2019.]

Zeh, Juli. 2016. Unterleuten. Múnich: Luchterhand. 